\title{
PD-L1 expression in tumor tissue and peripheral blood of patients with oral squamous cell carcinoma
}

\author{
Manuel Weber ${ }^{1}$, Falk Wehrhan' ${ }^{1}$ Christoph Baran', Abbas Agaimy², Maike Büttner- \\ Herold $^{3}$, Raimund Preidl ${ }^{1}$, Friedrich W. Neukam ${ }^{1}$ and Jutta Ries ${ }^{1}$ \\ ${ }^{1}$ Department of Oral and Maxillofacial Surgery, Friedrich-Alexander University Erlangen-Nürnberg, Erlangen, Germany \\ ${ }^{2}$ Institute of Pathology, Friedrich-Alexander University Erlangen-Nürnberg, Erlangen, Germany \\ ${ }^{3}$ Institute of Pathology, Department of Nephropathology, Friedrich-Alexander University Erlangen-Nürnberg, Erlangen, Germany \\ Correspondence to: Manuel Weber, email: manuel.weber@uk-erlangen.de
}

Keywords: $P D-L 1, m R N A, P C R, O S C C$, peripheral blood

Received: August 29, $2017 \quad$ Accepted: October 05, $2017 \quad$ Published: November 08, 2017

Copyright: Weber et al. This is an open-access article distributed under the terms of the Creative Commons Attribution License 3.0 (CC BY 3.0), which permits unrestricted use, distribution, and reproduction in any medium, provided the original author and source are credited.

\section{ABSTRACT}

Background: Immune checkpoints like programmed cell death-1 (PD-1) and its ligand PD-L1 are involved in immune escape mechanisms of solid tumors including oral squamous cell carcinoma (OSCC). Inhibitors of the pathway are successfully used for treating especially advanced disease. However, the physiological relevance of PD-1/PD-L1-signaling in OSCC is insufficiently understood. The aim of the study was to analyze if PD-L1 expression in tumor tissue and peripheral blood samples of OSCC patients is associated with histomorphological tumor parameters and if PD-L1 expression in patients is different from controls.

Results: OSCC tumor specimens showed a significantly higher PD-L1 expression than oral mucosa controls ( $p<0.001$; upregulation more than 3 -fold). Crosstabulation revealed an association of increased expression of PD-L1 mRNA in tissue specimens with malignancy $(p<0.001)$.

OSCC cases with higher tumor grade and cases with lymph node metastases $(\mathrm{N}+)$ were significantly $(p<0.05)$ associated with increased PD-L1 expression in peripheral blood. Cross-tabulation revealed an significant association with lymph node metastases $(\mathrm{N}+)(p \leq 0.002)$.

Materials and Methods: PD-L1 mRNA expression was analyzed in tumor specimens and corresponding samples of healthy oral mucosa and peripheral blood of 45 OSCC patients and 36 healthy control persons using RT-qPCR analysis. A Mann-Whitney $U$-test, a cut-off point analysis and a Chi-square test were carried out.

Conclusions: PD-L1 expression in OSCC could contribute to the immunosuppressive local tumor microenvironment. Increased malignant behavior (higher tumor grade, positive nodal status) might be associated with PD-L1 mediated systemic immune tolerance. Thus, PD-L1 expression in peripheral blood might be an indicator of the existence of metastatic disease $(\mathrm{N}+)$ in OSCC.

\section{INTRODUCTION}

There is emerging evidence that in addition to the biology of the tumor cell itself, the clinical course of malignant tumors is significantly influenced by the host immune response against cancer cells [1].

Although oral squamous cell carcinomas (OSCC) are highly immunogenic tumors [2], an effective host defense reaction is not observed. One reason is the presence of an immune tolerant tumor microenvironment [3, 4]. The current prognostic assessment of malignant tumors using the TNMscore does exclusively describe parameters of the neoplastic tissue and neglects the interaction between tumor and host [5]. Therefore, new complementary "immune-scoring" systems including host derived immune response and immune tolerance towards the neoplastic disease are needed [5]. 
Immune tolerance is mediated by inhibitory signaling pathways, so called immune checkpoints. The programmed cell death-1 (PD-1) and the PD-1 ligand (PD-L1) pathway is one of the most relevant immunologic checkpoints [6], that is involved in the immune escape mechanism of solid tumors like OSCC. PD-L1 binds to PD-1, a cell surface receptor expressed by activated T-cells and macrophages, and induces apoptosis of these immune cells [7] or formation of regulatory T-cells. Thus, overexpression of PD-L1 leads to immunosuppression $[6,8]$.

A constitutively high PD-L1 expression is seen in macrophages in immune privileged tissues like placenta and retina [6]. Besides immune cells, tumor cells can also express PD-L1 which might contribute to their immunosuppressive microenvironment [9].

An increased PD-L1 expression could already be shown in several solid malignancies like breast cancer, colon cancer or esophageal cancer [7]. Recent immunohistochemical studies indicate a possible connection between high PD-L1 expression in OSCC specimens and the occurrence of lymph node metastases $[10,11]$ and unfavorable prognosis [11-13]. These studies indicated that most but not all OSCC cases express PD-L1.

The emerging pharmacologic class of "checkpoint inhibitors" block suppressive immune signaling pathways like the PD-1/PD-L1 pathway. Current clinical studies investigating those "checkpoint inhibitors" for treatment of advanced clinical stages of solid malignancies revealed encouraging success rates that were not reached by any other second line treatment regime [14-16]. If patients respond to "checkpoint inhibitors", the remission phases seem to be more durable than could be achieved by any other previous treatment [17] making "checkpoint inhibitors" the currently most promising approach for cancer immunotherapy.

In the meanwhile those therapies are standard treatment for advanced melanoma and non-small cell lung cancer [3]. In addition, there are several late phase clinical trials including patients with recurrent or metastatic head and neck squamous cell carcinomas (HNSCC) $[18,19]$. In studies, targeting the PD-1/PD-L1 pathway by specific antibodies a significantly improved overall survival and quality of life could be shown [14]. Recently, inhibitors of the PD-1/PD-L1 pathway were approved in the US and the EU for advanced HNSCC refractory to platinum-based chemotherapy [20, 21]. Current protocols targeting the PD-1/PD-L1 pathway achieve response rates of up to $30 \%$ [22]. The fact that response rates do not necessarily correlate with the immunohistochemical detection of PD-L1 expression in tumor tissue [23, 24], outlines that the physiological relevance of PD/PD-L1 signaling is still insufficiently understood [23]. Hence, the clinical use of checkpoint therapies is more advanced than the fundamental biological understanding of immune regulation. For this reason, it is necessary to understand if PD-L1 mediated immune tolerance is a local phenomenon of the tumor microenvironment or a systemic condition. Thus, combined analysis of PD-L1 expression in tumor tissue and peripheral blood might be helpful. This analysis could contribute to an "immune-scoring" of OSCC that goes beyond TNM- classification and accommodates recent immune therapy strategies.

The current study was designed to clarify, if PDL1 expression is altered in cancer tissue compared to healthy oral mucosal and in peripheral blood samples of OSCC patients in comparison to peripheral blood of healthy control persons. It was addressed, if a cut-off point (COP) can be determined allowing the differentiation of OSCC patients from healthy controls based on the PD-L1 expression in tissue or peripheral blood. Additionally, a possible association between PD-L1 expression in tissue or peripheral blood with histomorphological parameters (T-, N-, L-, Pn-status, tumor grade) was tested.

\section{RESULTS}

\section{Clinical and histomorphological parameters of the analyzed cases}

Tissue specimens (OSCC and heathy oral mucosa) and whole blood samples of 45 OSCC patients (group patients) and 36 healthy volunteers (group controls) were collected. Demographic characteristics of all participants and histomorphological parameters of all OSCC patients are documented in Table 1. 29 males and 16 females were included in the patients group. The control group consisted of 24 males and 12 females. Mean age was 64.6 years (SD 12.5 ) in the patients group and 57.7 years (SD 20.7) in the control group (Table 1).

\section{Comparison of PD-L1 expression in tissue and blood between OSCC patients and healthy volunteers}

Data were derived from RT-qPCR and are presented as $\triangle \mathrm{CT}$ values. PD-L1 expression in tissue samples was normally distributed. Shapiro-Wilk testing revealed a $p$-value of 0.365 for PD-L1_4 and 0.177 for PD-L1_2 in tissue specimens. In blood samples, PD-L1 expression was not normally distributed. Shapiro-Wilk testing revealed $p$-values $<0.001$ for both PD-L1_4 and PD-L1_2 in blood samples. Using the Mann-Whitney U test, OSCC patients (group patients) and healthy controls (group controls) were tested for significant differences of mRNA expression for the transcript variants 1, 2 and 4 of PD-L1. In the analyses, expression of two isoforms of the gene was analyzed simultaneously (PDL1 variants 1 and 2 named PD-L1_2 and PD-L1variants 1 and 4 named PD-L1_4) (Table 2). Higher $\Delta \mathrm{CT}$ values indicate lower mRNA expression (Table 3).

Both analyzed PD-L1 variants (PD-L1_4 and PD-L1_2) showed significantly increased expression in OSCC compared to normal oral mucosa (mean PD-L1_4 $\Delta \mathrm{CT}$ patients 7.15 , mean PD-L1_4 $\Delta \mathrm{CT}$ controls $8.82 ; p$ $=0.001$; mean PD-L1_2 $\Delta \mathrm{CT}$ patients 9.25 , mean PD- 
Table 1: Description of the patient collective; total number of cases: 81

\begin{tabular}{|c|c|c|c|c|c|}
\hline & & \multicolumn{2}{|c|}{ patients } & \multicolumn{2}{|c|}{ controls } \\
\hline & & $n$ & $\%$ of cases & $n$ & $\%$ of cases \\
\hline number of cases & & 45 & & 36 & \\
\hline \multirow[t]{2}{*}{ gender } & male & 29 & 64.4 & 24 & 66.7 \\
\hline & female & 16 & 35.6 & 12 & 33.3 \\
\hline mean age & & \multicolumn{2}{|c|}{64.6 years (SD 12.5) } & \multicolumn{2}{|c|}{57.7 years (SD 20.7) } \\
\hline age range & & \multicolumn{2}{|c|}{ 35-93 years } & & \\
\hline \multirow[t]{3}{*}{ T-status } & $\mathrm{T} 1-\mathrm{T} 2$ & 24 & 53.3 & & \\
\hline & $\mathrm{T} 3-\mathrm{T} 4$ & 19 & 42.2 & & \\
\hline & unknown & 2 & 4.4 & & \\
\hline \multirow[t]{3}{*}{ N-status } & No & 25 & 55.6 & & \\
\hline & $\mathrm{N}+$ & 18 & 40 & & \\
\hline & unknown & 2 & 4.4 & & \\
\hline \multirow[t]{3}{*}{ L-status } & L0 & 32 & 71.1 & & \\
\hline & L1 & 11 & 24.4 & & \\
\hline & unknown & 2 & 4.4 & & \\
\hline \multirow[t]{3}{*}{ Pn-status } & Pn0 & 23 & 51.1 & & \\
\hline & Pn1 & 20 & 44.4 & & \\
\hline & unknown & 2 & 4.4 & & \\
\hline \multirow[t]{4}{*}{ grading } & G1 & 6 & 13.6 & & \\
\hline & G2 & 27 & 60 & & \\
\hline & G3 & 11 & 24.4 & & \\
\hline & unknown & 1 & 2.2 & & \\
\hline \multirow[t]{3}{*}{ clinical stage } & early & 16 & 35.6 & & \\
\hline & late & 27 & 60 & & \\
\hline & unknown & 2 & 4.4 & & \\
\hline
\end{tabular}

Demographic characteristics of OSCC patients (group patients) and healthy volunteers (group controls). For the OSCC patients group, staging parameters (T-, N-, L-, Pn-status, grading, clinical UICC stage) are shown.

L1 $2 \Delta$ CT controls $10.92 ; p<0.001$ ) (Table 3, Figure $1 \mathrm{~A}, 1 \mathrm{~B})$. These values indicate a significant 3.19 -fold upregulation of PD-L1_4 and a significant 3.18-fold upregulation of PD-L1_2 expression in OSCC compared to oral mucosa (Table 3). Hence, the biological active isoforms of PD-L1 were over expressed in OSCC.

In order to confirm the statistical relevance, ROC curves (Figure 1C and 1D) were generated and the AUC was determined. The upregulated PD-L1_4 yielded an AUC of 0.83 (Table 3, Figure 1C) and the upregulated PDL1_2 reached an AUC of 0.76 (Table 3, Figure 1D). Thus, this analysis confirmed that both PD-L1 mRNA variants were of significant diagnostic value for discrimination between healthy volunteers and OSCC patients.

The highest Youden indices were 0.643 for PD-L1_4 and 0.486 for PD-L1_2 (Figure 1C and 1D). The optimal threshold values (COPs) expressed in $\triangle \mathrm{CT}$ standards for distinguishing the patients from the healthy controls were
7.99 for PD-L1_4 and 10.37 for PD-L1_2 (Table 3). For all PD-L1 mRNA splice variants (PD-L1_4 and PD-L1_2), a $\triangle \mathrm{CT}$ value lower than the COP (upregulated PD-L1 expression) was considered to be positive for malignancy. Using the determined COPs, the two groups (patients and controls) were divided into positive and negative specimens in order to confirm that these parameters allow the detection of malignancy in a certain sample. The statistical evaluation by the Chi-square test revealed that the increased expression rates of PD-L1 mRNA were statistically relevantly associated with malignancy. The results are summarized in Table 3 and illustrated in Figure $1 \mathrm{E}$ and $1 \mathrm{~F}$.

Out of the OSCC patients, $81.4 \%$ (35/43) showed increased PD-L1_4 expression and 74.4\% (32/43) exhibited increased PD-L1_2 expression. In contrast, only $17.1 \%$ and $25.8 \%$ of the control samples (normal mucosa) showed increased PD-L1_4 and PD-L1_2 expression, respectively 
Table 2: Real-time qPCR Primer

\begin{tabular}{lcccc}
\hline \multicolumn{1}{c}{ Primer } & \multicolumn{1}{c}{ Sequence $\left(\mathbf{5}^{\prime}\right.$ to $\left.\mathbf{3}^{\prime}\right)$} & Primer $(\mathbf{b p )}$ & $\begin{array}{c}\text { Annealing } \\
\text { Amplicon (bp) }\end{array}$ & $\begin{array}{c}\text { temperature } \\
\left({ }^{\circ} \mathbf{C}\right)\end{array}$ \\
\hline PD-L1_2*'s & AGACCACCACCACCAATTCC & 20 & 173 & 60 \\
PD-L1_2* /as & TGGAGGATGTGCCAGAGGTA & 20 & - & - \\
PD-L1_4**/s & AGCTATGGTGGTGCCGACTA & 20 & 152 & 60 \\
PD-L1_4**/as & CAGATGACTTCGGCCTTGGG & 20 & - & - \\
GAPDH in /s & GACCCCTTCATTGACCTCAACTA & 23 & 102 & 60 \\
GAPDH in /as & GAATTTGCCATGGGTGGAAT & 20 & - & - \\
\hline
\end{tabular}

"amplification of transcript variant 1 and 2 simultaneously; amplicon named PD-L1_2

**amplification of transcript variant 1 and 4 simultaneously; amplicon named PD-L1 4

The selected primers for RT-qPCR mRNA expression analyses of PD-L1_4 (including PD-L1 splicing variants 1 and 4) and PD-L1_2 (including PD-L1 splicing variants 1 and 2).

(Table 3, Figure 1E and 1F). The correlation of malignancy and the detection of increased PD-L1 expression rates in tissue specimens were significant for both PD-L1 mRNA variants $(p<0.001)$ (Table 3$)$. Thus, increased expression of PD-L1 mRNA in tissue specimens was significantly associated with malignancy and may indicate the existence of OSCC. A sensitivity of $81.4 \%$ and a specificity of $82.9 \%$ were determined for PD-L1 4 expression. For PDL1_2 a sensitivity of $74.4 \%$ and a specificity of $74.2 \%$ were calculated (Table 5). Data for positive- and negative predictive value of PD-L1 expression for diagnosis of malignancy are given in Table 5.

In contrast to the described results in tissue specimens, there was no significant difference in PD-L1 mRNA expression with regard to blood samples of OSCC patients and healthy controls (PD-L1 4: mean $\triangle \mathrm{CT}$ patients 6.90 , mean $\Delta \mathrm{CT}$ controls $7.17 ; p=0.165$; PDL1_2: mean $\Delta \mathrm{CT}$ patients 6.92, mean $\Delta \mathrm{CT}$ controls 7.10; $p=0.287$ ) (Table 3).

\section{Association of PD-L1 expression in tissue and blood samples with histomorphological parameters (T-, N-, L-, Pn-status, grading) of OSCC patients}

Using Mann-Whitney U test, comparison of PDL1 mRNA expression in tissue specimens (OSCC tumor and normal oral mucosa) regarding histomorphological parameters (T-, N-, L-, Pn-status, grading) revealed no significant associations. Higher $\Delta \mathrm{CT}$ values indicate lower mRNA expression (Table 4).

Expression of both analyzed PD-L1 variants (PDL1_4 and PD-L1_2) in whole blood samples of OSCC patients was significantly higher in cases with lymph node metastases $(\mathrm{N}+)$ compared to cases without lymph node metastases (N0) (mean PD-L1_4 $\Delta \mathrm{CT} \mathrm{N}+6.29$, mean PDL1_4 $\Delta$ CT N0 7.35; $p=0.002$; mean PD-L1_2 $\Delta \mathrm{CT}$ N + 6.30 , mean PD-L1_2 $\Delta$ CT N0 7.37; $p=0.003$ ) (Table 4,
Figure 2A, 2B). These values indicate a significant 2.09-fold upregulation of PD-L1_4 expression and a significant 2.1fold upregulation of PD-L1_2 expression in peripheral blood of $\mathrm{N}+\mathrm{OSCC}$ patients compared to N0 patients (Table 4).

In order to confirm the statistical relevance, ROC curves (Figure 2C and 2D) were generated and the AUC was determined. Upregulated PD-L1_4 mRNA yielded an AUC of 0.79 (Table 4, Figure 2C) and upregulated PD-L1_2 mRNA reached an AUC of 0.77 (Table 4, Figure 2D). Thus, this analysis confirmed that both PDL1 mRNA variants were of significant diagnostic value for discrimination of $\mathrm{N}+$ and N0 OSCC patients using peripheral blood samples. The results showed a statistically significant association between PD-L1 overexpression and the prevalence of lymph node metastases $(\mathrm{N}+)$.

The highest Youden indices were 0.486 for PD-L1_4 and 0.5 for PD-L1_2 (Figure 2C and 2D). The optimal threshold values (COPs) expressed in $\triangle \mathrm{CT}$ standards for distinguishing the $\mathrm{N}+$ patients from $\mathrm{N} 0$ patients were 7.14 for PD-L1 4 and 7.04 for PD-L1 2. For both PD-L1 mRNA variants (PD-L1_4 and PD-L1_2), a $\Delta \mathrm{CT}$ under the COP (upregulated) was considered to be positive for lymph node metastases $(\mathrm{N}+)$ corresponding to an increased expression level in peripheral blood samples. Using the determined COPs, the two groups $(\mathrm{N}+$ and $\mathrm{N} 0$ patients) were divided into positive and negative lesions in order to confirm that PD-L1 expression in blood allowed the detection of lymph node metastases ( $\mathrm{N}+$ status). The statistical evaluation by the Chi-square test revealed that increased expression rates of PD-L1 mRNA in peripheral blood were significantly associated with the presence of lymph node metastases ( $\mathrm{N}+$ status). The results are summarized in Table 4 and illustrated in Figure 2E and 2F. Regarding the diagnosis of positive $\mathrm{N}$-status $(\mathrm{N}+)$, a sensitivity of $94.4 \%$ and a specificity of $54.2 \%$ were determined for PD-L1_4 expression in blood samples. For PD-L1_2 a sensitivity of $83.3 \%$ and a specificity of $66.7 \%$ were calculated (Table 5). Data for positive- and negative 
Table 3: PD-L1 expression in tissue and peripheral blood of healthy controls and OSCC patients

\begin{tabular}{lccccccccccccc}
\hline & $\boldsymbol{n}$ & $\begin{array}{c}\text { mean } \\
\Delta \mathbf{C T}\end{array}$ & SD & $\boldsymbol{p}$-value & AUC & $\mathbf{F C}$ & $\mathbf{C O P}$ & $\begin{array}{c}\text { No. of } \\
\text { cases }\end{array}$ & + & $\begin{array}{c}\text { \% } \\
\text { pos. } \\
\text { cases }\end{array}$ & $\begin{array}{c}\boldsymbol{p} \text {-value } \\
\chi^{2} \text { test }\end{array}$ \\
\hline $\begin{array}{l}\text { PD-L1_4 tissue } \\
\text { controls }\end{array}$ & 78 & & & $<0.001$ & 0.83 & 3.19 & 7.99 & 78 & 41 & 37 & & $<0.001$ \\
patients & 35 & 8.82 & 1.11 & & & & & 35 & 6 & 29 & $17.1 \%$ & \\
PD-L1_4 blood & 43 & 7.15 & 1.59 & & & & & 43 & 35 & 8 & $81.4 \%$ & \\
controls & 75 & & & 0.165 & nd & nd & nd & nd & nd & nd & nd & nd \\
patients & 31 & 7.17 & 1.40 & & & & & & & & & \\
PD-L1_2 tissue & 44 & 6.90 & 1.24 & & & & & & & & & \\
controls & 74 & & & $<0.001$ & 0.76 & 3.18 & 10.37 & 74 & 40 & 34 & & $<0.001$ \\
patients & 31 & 10.92 & 1.45 & & & & & 31 & 8 & 23 & $25.8 \%$ & \\
PD-L1_2 blood & 43 & 9.25 & 1.94 & & & & & 43 & 32 & 11 & $74.4 \%$ & \\
controls & 75 & & & 0.287 & nd & nd & nd & nd & nd & nd & nd & nd \\
patients & 31 & 7.10 & 1.33 & & & & & & & & & \\
\hline
\end{tabular}

Comparison of PD-L1 mRNA expression between OSCC patients (group patients) and healthy volunteers (group controls). Expression of PD-L1 splicing variants 1 and 4 (PD-L1_4) and splicing variants 1 and 2 (PD-L1_2) in tissue (OSCC tumor tissue vs. healthy oral mucosa of volunteers) and peripheral blood was analyzed. The mean $\Delta \mathrm{CT}$ value (mean), standard deviation (SD) and the p-value provided by the Mann-Whitney $U$ test are shown. Higher $\Delta \mathrm{CT}$ values indicate lower PD-L1 mRNA expression. Regarding PD-L1 expression in tissue, area under the curve (AUC), fold-change FC and cut-off point (COP) values are given. Based on their $\triangle \mathrm{CT}$ value related to the $\mathrm{COP}$, the cases were determined as positive (malignant) and negative (healthy). The percentage of positive tested cases (\% pos. cases) in the controls and patients group is presented. A Statistical analysis was carried out by the Chi-square test ( $\chi^{2}$ test). Fold-change (FC) of PD-L1 mRNA expression was determined by the $\Delta \Delta \mathrm{CT}$ method comparing the average $\Delta \mathrm{CT}$ values of the two groups. nd: not determined.

predictive value of PD-L1 expression in blood samples for diagnosis of positive $\mathrm{N}$-status $(\mathrm{N}+)$ are given in Table 5.

Additionally, there was a significant association between PD-L1 mRNA expression in blood samples and the histologically determined tumor grading. PD-L1_4 expression in blood samples of $\mathrm{G} 3$ cases was significantly higher than in samples of G1 cases (mean PD-L1_4 $\Delta \mathrm{CT}$ : G3 6.47, G1 7.71; $p=0.020$ ) (Table 4, Figure 3A). PD-L1_2 expression in blood of $\mathrm{G} 3$ cases was significantly higher than in $\mathrm{G} 1$ cases $(p=$ $0.010)$ and in $\mathrm{G} 2$ cases $(p=0.031)$ (mean PD-L1_2 $\Delta \mathrm{CT}$ : G3 6.42, G2 6.93, G1 7.79) (Table 4, Figure 3B).

There was no significant association between the altered blood expression of PD-L1 mRNA and tumor size $(\mathrm{T} 1 / \mathrm{T} 2$ vs. T3/T4) $(p>0.05)$. Moreover, no significance was shown with regard to changes in blood expression rates of PD-L1 mRNA and histologically proven lymph vessel infiltration (L-status) or perineural infiltration (Pn-status). The results of statistical assessment are summarized in Table 4.

\section{DISCUSSION}

\section{PD-L1 expression in healthy individuals and OSCC patients}

The current study revealed an increased PD-L1 mRNA expression in OSCC tumor tissue compared to healthy oral mucosa. PD-L1 signaling leads to an inhibition of T-cell activation and proliferation [16] which promotes the immune escape of the tumor. The detected increase of PD-L1 expression in OSCC tissue might originate from tumor cells as well as from tumor infiltrating immune cells and can be an indicator of the tumor-induced local immunosuppressive microenvironment.

It is assumed that tumor cells upregulate PD-L1 expression to evade the host immune reaction and thereby to increase their survival rate [28]. PD-L1 expression in tumor cells is induced intrinsically by oncogenic signaling pathways and extrinsically by factors of the tumor microenvironment [23, 28]. Activation of the oncogenic MAPK signaling pathway was shown to be an intrinsic activator of PD-L1 expression [23, 29]. Tumor hypoxia is one extrinsic driver of PD-L1 upregulation. Increased levels of the hypoxia-associated transcription factor Hifl $\alpha$ were shown to be associated with high PD-L1 expression [23]. Additionally, different growth factors [23] as well as cytokines [28] can modulate PD-L1 expression of tumor cells. The results of the current study indicate that PD-L1 expression increases at a certain point or period during malign transformation of oral mucosa to OSCC.

We detected PD-L1 mRNA expression in all analyzed OSCC specimens and in all samples of control mucosa tissue. PD-L1 expression in OSCC was previously 
Table 4: PD-L1 expression in peripheral blood of OSCC patients related to histomorphological parameters (T-, N-, L-, Pn-status, grading)

\begin{tabular}{|c|c|c|c|c|c|c|c|c|c|c|c|c|c|}
\hline & & $n$ & $\begin{array}{c}\text { mean } \\
\Delta \mathrm{CT}\end{array}$ & SD & p-value & AUC & FC & COP & $\begin{array}{l}\text { No. of } \\
\text { cases }\end{array}$ & + & - & $\%$ pos. cases & $p$-value $\chi^{2}$ test \\
\hline & PD-L1_4 blood & 42 & & & 0.370 & nd & nd & nd & nd & nd & nd & nd & nd \\
\hline \multirow[t]{6}{*}{ T-status } & $\mathrm{T} 1-\mathrm{T} 2$ & 23 & 6.87 & 1.54 & & & & & & & & & \\
\hline & $\mathrm{T} 3-\mathrm{T} 4$ & 19 & 6.93 & 0.90 & & & & & & & & & \\
\hline & PD-L1_2 blood & 42 & & & 0.487 & nd & nd & nd & nd & nd & nd & nd & nd \\
\hline & $\mathrm{T} 1-\mathrm{T} 2$ & 23 & 6.89 & 1.45 & & & & & & & & & \\
\hline & $\mathrm{T} 3-\mathrm{T} 4$ & 19 & 6.94 & 0.94 & & & & & & & & & \\
\hline & PD-L1_4 blood & 42 & & & 0.002 & 0.79 & 2.09 & 7.14 & 42 & 28 & 14 & & 0.001 \\
\hline \multirow[t]{6}{*}{ N-status } & No & 24 & 7.35 & 0.99 & & & & & 24 & 11 & 13 & $45.8 \%$ & \\
\hline & $\mathrm{N}+$ & 18 & 6.29 & 1.38 & & & & & 18 & 17 & 1 & $94.4 \%$ & \\
\hline & PD-L1_2 blood & 42 & & & 0.003 & 0.77 & 2.1 & 7.04 & 42 & 23 & 19 & & 0.002 \\
\hline & N0 & 24 & 7.37 & 0.90 & & & & & 24 & 8 & 16 & $33.3 \%$ & \\
\hline & $\mathrm{N}+$ & 18 & 6.30 & 1.37 & & & & & 18 & 15 & 3 & $83.3 \%$ & \\
\hline & PD-L1_4 blood & 42 & & & 0.590 & nd & nd & nd & nd & nd & nd & nd & nd \\
\hline \multirow[t]{6}{*}{ L-status } & L0 & 32 & 6.90 & 1.40 & & & & & & & & & \\
\hline & L1 & 10 & 6.89 & 0.78 & & & & & & & & & \\
\hline & PD-L1_2 blood & 42 & & & 0.154 & nd & nd & nd & nd & nd & nd & nd & nd \\
\hline & L0 & 32 & 6.96 & 1.35 & & & & & & & & & \\
\hline & L1 & 10 & 6.76 & 0.81 & & & & & & & & & \\
\hline & PD-L1_4 blood & 42 & & & 0.441 & nd & nd & nd & nd & nd & nd & nd & nd \\
\hline \multirow[t]{6}{*}{ Pn-status } & Pno & 23 & 6.89 & 1.56 & & & & & & & & & \\
\hline & Pn1 & 19 & 6.90 & 0.86 & & & & & & & & & \\
\hline & PD-L1_2 blood & 42 & & & 0.441 & nd & nd & nd & nd & nd & nd & nd & nd \\
\hline & Pn0 & 23 & 6.91 & 1.51 & & & & & & & & & \\
\hline & Pn1 & 19 & 6.91 & 0.82 & & & & & & & & & \\
\hline & PD-L1_4 blood & 43 & & & & nd & nd & nd & nd & nd & nd & nd & nd \\
\hline \multirow[t]{7}{*}{ grading } & G1 & 6 & 7.71 & 1.27 & & \multicolumn{3}{|c|}{$p$-value G1 vs. G2: 0.119} & & & & & \\
\hline & G2 & 26 & 6.90 & 1.35 & & \multicolumn{3}{|c|}{$p$-value $\mathrm{G} 1$ vs. G3: 0.020} & & & & & \\
\hline & G3 & 11 & 6.47 & 0.83 & & \multicolumn{3}{|c|}{$p$-value G2 vs. G3: 0.087} & & & & & \\
\hline & PD-L1_2 blood & 43 & & & & nd & nd & nd & nd & nd & nd & nd & nd \\
\hline & G1 & 6 & 7.79 & 1.02 & & \multicolumn{3}{|c|}{$p$-value G1 vs. G2: 0.207} & & & & & \\
\hline & G2 & 26 & 6.93 & 1.31 & & \multicolumn{3}{|c|}{$p$-value $\mathrm{G} 1$ vs. G3: 0.010} & & & & & \\
\hline & G3 & 11 & 6.42 & 0.83 & & \multicolumn{3}{|c|}{$p$-value $\mathrm{G} 2$ vs. G3: 0.031} & & & & & \\
\hline
\end{tabular}

Association between the PD-L1 mRNA expression rates in peripheral blood samples of OSCC patients and histomorphological parameters (T-, N-, L-, Pn-status, grading). Data for PD-L1 splicing variants 1 and 4 (PD-L1_4) and splicing variants 1 and 2 (PD-L1_2) are given. The mean $\Delta \mathrm{CT}$ value (mean), standard deviation (SD) and the p-value provided by the Mann-Whitney U test are shown. Higher $\Delta \mathrm{CT}$ values indicate lower PD-L1 mRNA expression. Regarding the N-status, area under the curve (AUC), fold-change FC and cut-off point (COP) values are given. Based on their $\triangle \mathrm{CT}$ value related to the COP, the cases were determined as positive $(+)$ and negative (-). The percentage of positive tested cases (\% pos. cases) in the N0 and N+ group is presented. A Statistical analysis was carried out by the Chi-square test $(\chi 2$ test). Fold-change (FC) of PD-L1 mRNA expression was determined by the $\Delta \Delta \mathrm{CT}$ method comparing the average $\Delta \mathrm{CT}$ values of the two groups. nd: not determined.

investigated in several immunohistochemical studies [10 13, 28, 30-32]. These studies report rates of PD-L1 positive cases from $18 \%$ to $87 \%$ [28]. The heterogeneity of these results might be explained by the use of different staining protocols and the subjective assigning of cut-off points to determine PD-L1 positivity $[18,28]$. To our knowledge, this is the first study determining PD-L1 mRNA expression in OSCC specimens compared to healthy controls. Moreover, a cut-off point was determined at which an overexpression of PD-L1 can be detected objectively.

Immunohistochemically identified PD-L1 positivity is often used as potential predictor for therapy response of PD-L1 or PD-1 targeting checkpoint inhibitors [28]. However, there is a large proportion of clinical cases with immunohistochemically positive tumor cells that do not respond to checkpoint inhibitor therapy [23, 24]. Genetic alterations associated with weakened or changed antigen presentation might lead to resistance to checkpoint inhibitors in some of these cases [33, 34]. On the contrary, there are tumors that do not express PD-L1 on the cell surface and respond to antibodies targeting the PD/PD-L1 pathway $[23,24]$. Immunocompetent mice bearing PD-L1 knockout tumors showed a significant treatment response to PD-L1 blocking antibodies with a long-term survival of nearly $90 \%$ [35]. Additionally, a recent flow cytometric analysis showed an increased expression of PD-L1 in tumor infiltrating lymphocytes in HNSCC [36]. These findings indicate that PD-L1 expression on immune cells might be of equal or of even higher biological relevance than on tumor cells $[35,37]$. 
Table 5: Sensitivity, specificity, positive- and negative predictive value of PD-L1 expression for diagnosis of malignancy and $\mathrm{N}$-status

\begin{tabular}{|c|c|c|c|c|c|c|c|}
\hline & & + & - & sensitivity & specificity & $\begin{array}{c}\text { positive } \\
\text { predictive } \\
\text { value }\end{array}$ & $\begin{array}{c}\text { negative } \\
\text { predictive } \\
\text { value }\end{array}$ \\
\hline \multirow{4}{*}{$\begin{array}{l}\text { Diagnose } \\
\text { (tissue) }\end{array}$} & $\begin{array}{c}\text { PD-L1_4 } \\
\text { tissue }\end{array}$ & & & \multirow{4}{*}{$81.4 \%$} & \multirow{4}{*}{$82.9 \%$} & \multirow{4}{*}{0.854} & \multirow{4}{*}{0.784} \\
\hline & controls & 6 & 29 & & & & \\
\hline & patients & 35 & 8 & & & & \\
\hline & $\begin{array}{c}\text { PD-L1_2 } \\
\text { tissue }\end{array}$ & & & & & & \\
\hline \multirow{8}{*}{$\begin{array}{l}\text { N-status } \\
\text { (blood) }\end{array}$} & controls & 8 & 23 & & & & \\
\hline & patients & 32 & 11 & $74.4 \%$ & $74.2 \%$ & 0.8 & 0.68 \\
\hline & $\begin{array}{c}\text { PD-L1_4 } \\
\text { blood }\end{array}$ & & & \multirow{5}{*}{$94.4 \%$} & \multirow{4}{*}{$54.2 \%$} & \multirow{4}{*}{0.607} & \multirow{4}{*}{0.929} \\
\hline & N0 & 11 & 13 & & & & \\
\hline & $\mathrm{N}+$ & 17 & 1 & & & & \\
\hline & $\underset{\text { blood }}{\text { PD-L1_2 }}$ & & & & & & \\
\hline & No & 8 & 16 & & & & \\
\hline & $\mathrm{N}+$ & 15 & 3 & $83.3 \%$ & $66.7 \%$ & 0.652 & 0.842 \\
\hline
\end{tabular}

The table shows sensitivity, specificity, positive- and negative predictive value of PD-L1 expression in tissue specimens for diagnosis of malignancy. (controls vs. patients) and of PD-L1 expression in blood samples for diagnosis of a positive N-status (N0 vs. $\mathrm{N}+$ ).

\section{Correlation of PD-L1 expression with histomorphological parameters in OSCC patients}

So far, there are no studies investigating PD-L1 expression in peripheral blood of tumor patients. In the current analysis, all tested peripheral blood samples of OSCC patients and healthy controls showed positive PD-L1 expression. Generally, PD-L1 is expressed on T-cells, dendritic cells and monocytes/macrophages $[3,19]$. Therefore, it is conceivable that these types of immune cells express PD-L1 in whole blood samples and that this expression could be altered in OSCC patients compared to healthy volunteers and additionally in patients suffering from different clinical stages of OSCC. In the here applied method all blood components were included in the expression analyses. PD-L1 expression of circulating tumor cells is therefore overlain by immune cell based PD-L1 expression [38-40]. Hence, changes in the immune response and possible systemic immune suppressive mechanisms in tumor progression could be assessed by PD-L1 expression analysis. Therefore, in the current analyses of blood samples, immune cell based PDL1 expression is expected to be more relevant than PD-L1 expression on disseminated tumor cells. However, in order to confirm this hypothesis further studies are required in which individual cell fractions of peripheral blood are isolated, characterized and examined for their PD-L1 expression. In the current study a significantly increased PD-L1 expression in the peripheral blood of OSCC patients with lymph node metastases $(\mathrm{N}+)$ was detected. Local PD-L1 expression is caused by tumor cells, healthy epithelial cells or inflammatory cells. Systemic PD-L1 expression detected in peripheral blood is presumably caused in large parts by circulating immune cells. Therefore, the detected association between lymph node metastases and high PD-L1 expression in peripheral blood of OSCC patients is an indicator that PD-L1 expression of immune cells might be of high biologic relevance.

As PD-L1 signaling leads to immunosuppression [37], the increased PD-L1 expression in blood samples of $\mathrm{N}+$ cases detected in the current study indicates that metastatic disease in OSCC patients might be associated with a PD-L1 mediated systemic state of immunosuppression. It is unclear if this is caused by the presence of metastatic tumor tissue or if a systemic state of PD-L1 mediated immune tolerance enables the formation of metastatic lesions in tumor draining lymph nodes. The fact that OSCC patients and healthy control persons do not differ regarding their PD-L1 expression in peripheral blood indicates that a tumor-independent, preexisting state of immune surveillance or PD-L1 
mediated immune tolerance might enable the formation of metastases in a certain subgroup of individuals. Thus, the systemic expression of PD-L1 might be an indicator of the competence - or incompetence - of the host organism to deal with the tumor.

The current study revealed no significant correlation between PD-L1 expression in OSCC tumor specimens
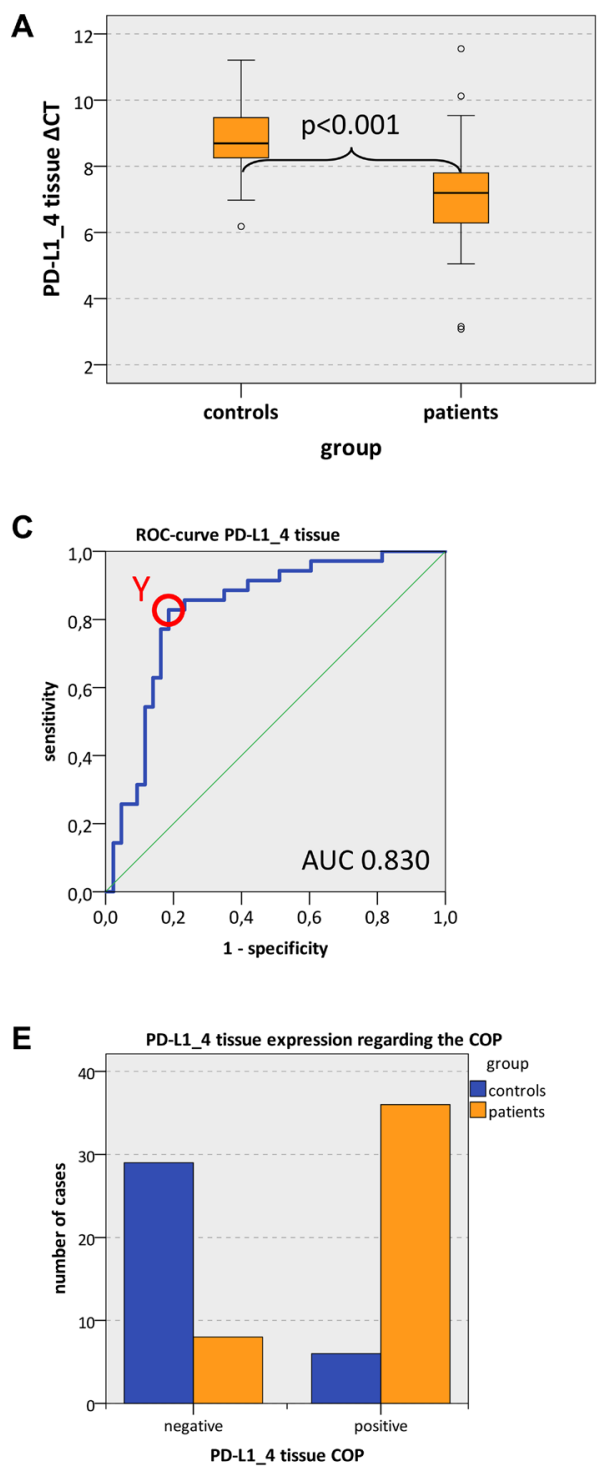

and histomorphological parameters. PD-L1 expression in tumor tissue is caused by tumor cells and by tumor infiltrating immune cells. Thus, in OSCC tumor samples, effects of different tumor cell derived PD-L1 expression could overlay the immune cell based association between N-status and PD-L1 expression that was detected in peripheral blood samples.
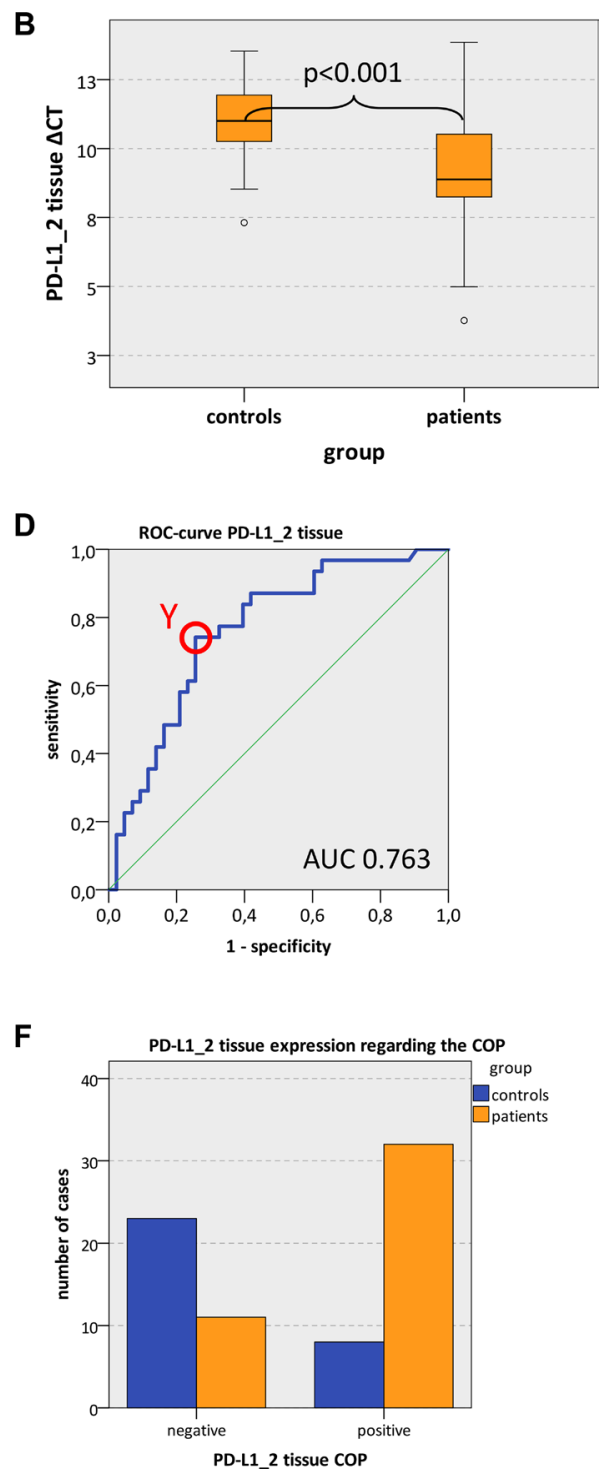

Figure 1: PD-L1 tissue expression in OSCC patients and healthy mucosal controls (A, B) Box plots of the median PD-L1 expression rates in tumor tissue of OSCC patients (group patients) and healthy oral mucosa of volunteers (group controls). The median $\triangle \mathrm{CT}$ values of PDL1 splicing variants 1 and 4 (PD-L1_4) (Figure 1A) and splicing variants 1 and 2 (PD-L1_2) (Figure 1B) derived from RT-qPCR are given. Higher $\triangle \mathrm{CT}$ values indicate lower PD-L1 mRNA expression. The median, the interquartile range and the standard deviation are provided. Statistical analyses were carried out by the Mann-Whitney U test. (C, D) ROC curves for PD-L1 mRNA expression based on the RT-qPCR data. The diagrams are a plot of the sensitivity (true-positive rate) vs. 1-specificity (false-positive rate) over all possible $\Delta C T$ values. Data for PD-L1 variant PD-L1_4 (Figure 1C) and variant PD-L1_2 (Figure 1D) are provided. The circles show the points of the highest Youden (Y) indices which are associated with the COP (patients vs. controls). The AUC value is indicated. ROC: receiver operating characteristic, COP: cut-off point, AUC: area under the curve.e, (F) Division of the test and control group (group patients and group controls) into positive and negative subgroups based on the ascertained COPs of PD-L1 variant PD-L1_4 (Figure 1E) and variant PD-L1_2 (Figure 1F) expressed as $\Delta \mathrm{CT}$ values. Using the $\chi^{2}$ test, the specimens were positively (malignant) judged if the values lied below the COP. Increased PD-L1_4 and PD-L1_2 expression levels in the tissue of OSCC patients (group patients) compared healthy oral mucosa of volunteers (group controls) were significant. Therefore, the COP may be a parameter allowing the allocation of a tissue sample to a group and the proof of malignancy. 
Macrophages are a possible source of PD-L1 expression in peripheral blood [37]. Previous studies showed an association between immune tolerant M2polarized macrophages and high PD-L1 expression in cancer specimens [41-43]. In the current analysis, we could detect an association between higher tumor grading and increased PD-L1 expression in peripheral blood samples. This finding could indicate that increased

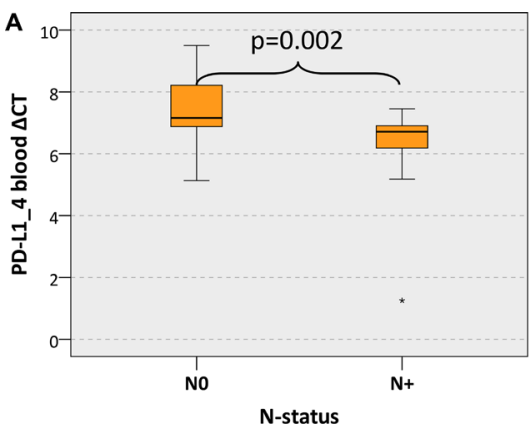

C
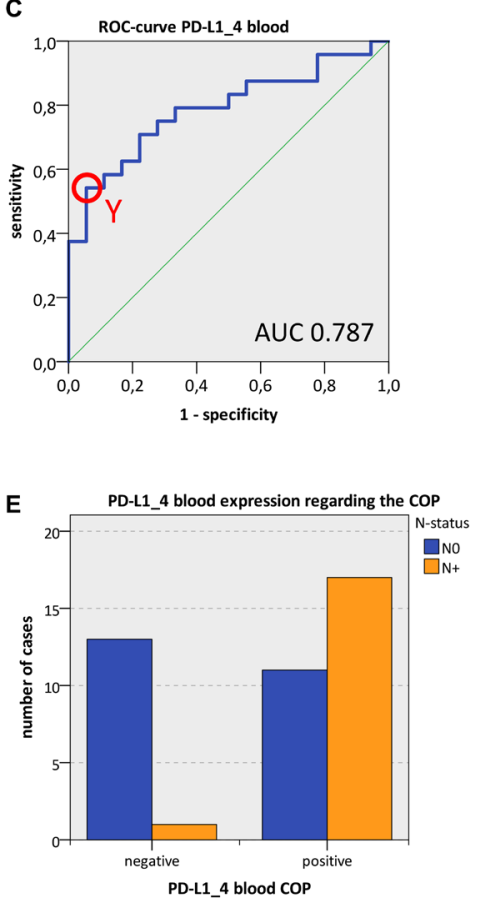

malign potential of the primary tumor correlates with an augmented degree of peripheral immune tolerance. In peripheral blood, OSCC patients and controls showed no difference in the number of CD14/CD16 expressing cells representing both M1- and M2-polarized macrophages [44]. However, we identified an association between markers of malignant behavior (grading, L-status, Pnstatus) in the primary tumor with a shift of macrophage

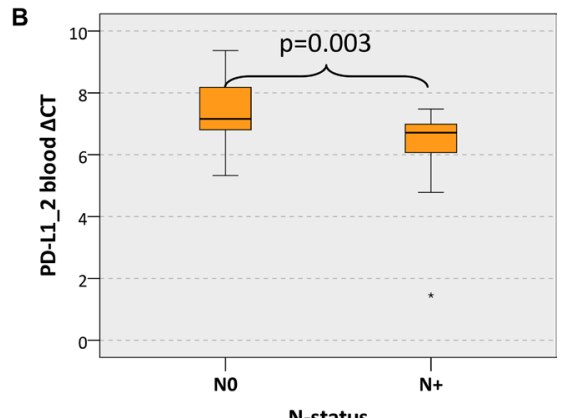

D
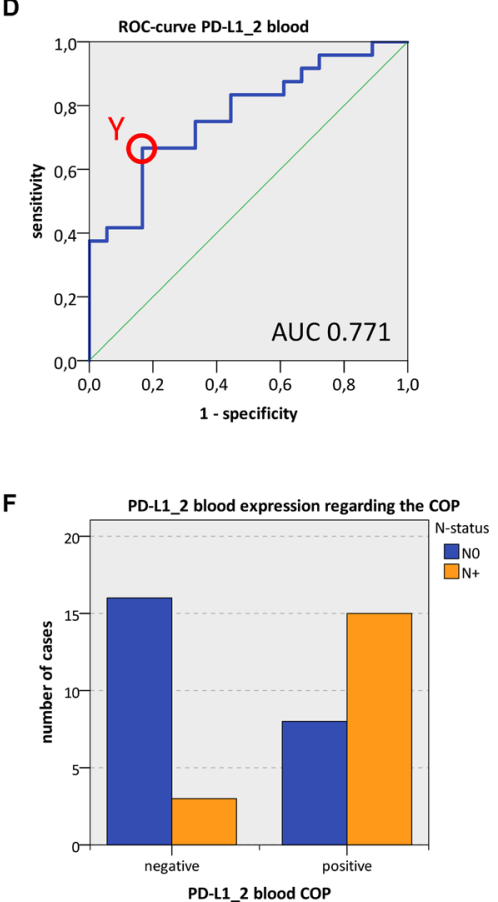

Figure 2: PD-L1 blood expression in OSCC patients depending on the N-status (A, B) Box plots of the median PD-L1 expression rates in peripheral blood of OSCC patients with lymph node metastases (group N+) and OSCC patients without lymph node metastases (group N0). The median $\triangle \mathrm{CT}$ values of PD-L1 splicing variants 1 and 4 (PD-L1_4) (Figure 2A) and splicing variants 1 and 2 (PD-L1_2) (Figure 2B) derived from RT-qPCR are given. Higher $\triangle \mathrm{CT}$ values indicate lower PD-L1 mRNA expression. The median, the interquartile range and the standard deviation are provided. Statistical analyses were carried out by the Mann-Whitney $U$ test. (C, D) ROC curves for PD-L1 mRNA expression based on the RT-qPCR data. The diagrams are a plot of the sensitivity (true-positive rate) vs. 1-specificity (false-positive rate) over all possible $\Delta C$ T values. Data for PD-L1 variant PD-L1 4 (Figure 2C) and variant PD-L1 2 (Figure 2D) are provided. The circle shows the point of the highest Youden (Y) index which is associated with the COP (N+vs. N0). The AUC value is indicated. ROC: receiver operating characteristic, COP: cut-off point, AUC: area under the curve. (E, F) Division of the test and control group (N+ OSCC cases and N0 OSCC cases) into positive and negative subgroups based on the ascertained COPs of PD-L1 variant PD-L1 4 (Figure 2E) and variant PD-L1_2 (Figure 2F) expressed as $\Delta \mathrm{CT}$ values. Using the $\chi^{2}$ test, the specimens were positively $(\mathrm{N}+$ ) judged if the values lied below the COP. Increased PD-L1_4 and PD-L1_2 expression levels in the peripheral blood of OSCC patients with lymph node metastases (group N+) compared to OSCC patients without lymph node metastases (group N0) were significant. Therefore, the COP may be a parameter allowing the allocation of a blood sample to a case with (group N+) or without (group N0) lymph node metastases. 
polarization in regional lymph nodes from the antitumoral M1 polarization towards the tumor-promoting M2 polarization in a previous study [45]. As M2 polarization of macrophages is also considered as an expression of immune tolerance [46] and M2 macrophages are characterized by PD-L1 expression [41, 42], it can be hypothesized that increased malignancy of the primary OSCC is associated with augmented peripheral immune tolerance. This hypothesis is supported by a recent in vitro analysis showing an increased PD-L1 expression in macrophages and dendritic cells co-cultured with high grade OSCC cells [3]. The relevance for OSCC is underlined by a further study showing increased PD-L1 expression in CD163 and CD204 positive M2 macrophages derived from OSCC patients in vitro [47].

\section{Limitations of the study}

As mRNA expression was analyzed, post transcriptional modifications might lead to an altered PDL1 protein expression.

The current study cannot determine to which extent the observed increase in PD-L1 expression in OSCC specimens is caused by tumor cells or by stromal cells and tumor-infiltrating immune cells. However, the increased PD-L1 expression in blood samples (PAXgene) of N+ OSCC cases seems to represent a condition of the host immune system. There is currently conflicting data regarding a positive or inverse correlation between PD-L1 expression and the infiltration of lymphocytes in OSCC $[28,30,31]$.

\section{Future perspectives}

It is not clear at which point during the tumorigenesis of OSCC PD-L1 expression is upregulated [23]. Therefore, analysis of PD-L1 expression in precursor lesions of OSCC

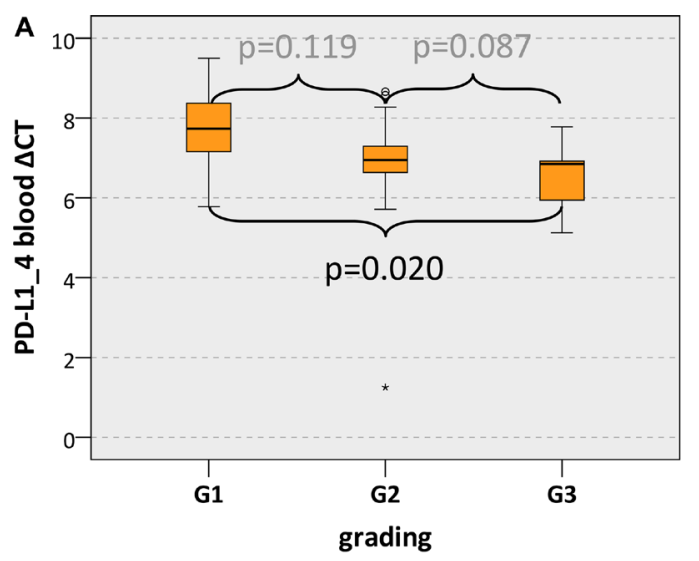

like oral leukoplakia and squamous dysplasia would be of great interest.

The question if PD-L1 expression on tumor cells or immune cells like macrophages is of higher relevance for the tumor immune-escape mechanism is not yet answered. Therefore, immunohistochemical analysis of the association between PD-L1 expression and macrophage polarization would be of interest.

Preclinical data indicate that a combination of PDL1 inhibition and radiotherapy is an effective treatment regime for OSCC [48]. Therefore, an analysis of PD-L1 expression in peripheral blood of OSCC patients before and after radiotherapy might give new insights to motivate future treatment studies.

Finally, the results of the current report could motivate to test the potential role of PD-L1 expression in blood as predictive biomarker for the presence of metastatic disease $(\mathrm{N}+)$ in OSCC patients in prospective studies.

\section{MATERIALS AND METHODS}

\section{Patients and sample collection}

The study was approved by the Ethics Committee of the University of Erlangen-Nuremberg, Erlangen, Germany (approval number: 3962) and patients' written informed consent was obtained. The study was performed in accordance with the Declaration of Helsinki.

Tissue specimens and peripheral blood samples were collected from 45 OSCC patients (group patients) and 36 healthy volunteers (group controls). Patients were only included in this study if they presented with OSCC for the first time. All samples were taken before any treatment (i.e. radiotherapy and/or chemotherapy). Demographic characteristics including age and gender of all study participants were documented and are shown in Table 1.

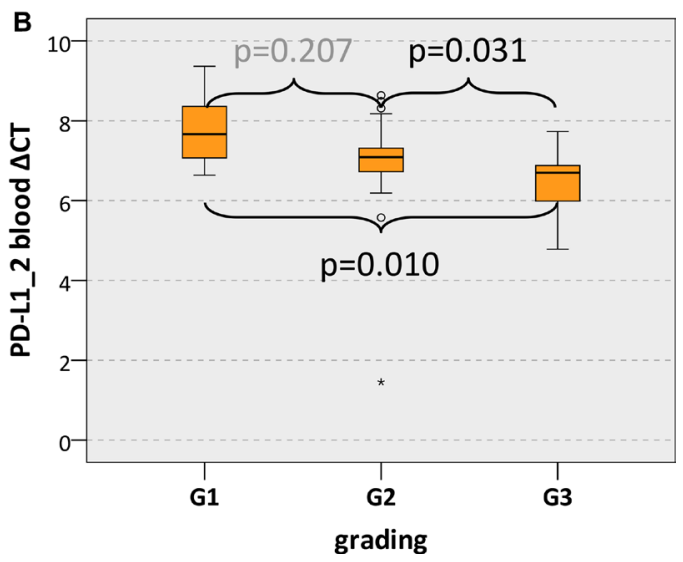

Figure 3: PD-L1 blood expression in OSCC patients depending on the grading Box plots of the median PD-L1 expression rates in peripheral blood of OSCC patients depending on the tumor grading (G1-G3). The median $\triangle \mathrm{CT}$ values of PD-L1 splicing variants 1 and 4 (PD-L1_4) (Figure 3A) and splicing variants 1 and 2 (PD-L1_2) (Figure 3B) derived from RT-qPCR are given. Higher $\triangle \mathrm{CT}$ values indicate lower PD-L1 mRNA expression. The median, the interquartile range and the standard deviation are provided. Statistical analyses were carried out by the Mann-Whitney $U$ test. 
Healthy volunteers were selected based on the absence of inflammation and malignant disease. Tissue samples of healthy volunteers were taken during dentoalveolar surgery after informed consent.

The diagnosis of OSCC was assigned through routine histopathological examination. Grading (G1G3; differentiation status), clinical UICC-stage (I-IV) and TNM classification of OSCC were documented in the histologic reports according to the guidelines of the most recent World Health Organization classification of tumors of the head and neck and the International Union Against Cancer [25, 26]. Clinical stages were grouped as early (stage I and II) and late (stage III and IV) stages. Additionally, lymph node status was grouped as N0 and $\mathrm{N}+$ to indicate absence $(\mathrm{N} 0)$ or presence $(\mathrm{N}+)$ of metastases, respectively. Additionally, subgroups were categorized based on tumor size and/or invasion dividing the samples into small/early (T1 and T2) and large/ advanced (T3 and T4) malignancies. Relevant clinical and histopathological parameters are summarized in Table 1. blood

Sampling of tumor specimens and whole peripheral

Tissue samples of healthy volunteers were obtained during minor surgery by avoiding additional incisions. In case of OSCC patients, tumor tissue samples were acquired during tumor resection. In order to conserve mRNAs after excision all tissue specimens were immediately transferred into RNAlater (Qiagen, Hilden, Germany) and were fixed by incubation at $4^{\circ} \mathrm{C}$ for at least 24 hours. Afterwards they were stored at $-80^{\circ} \mathrm{C}$ until mRNA isolation.

Additionally, two samples of $2.5 \mathrm{ml}$ whole peripheral blood were collected in a PAXgene Blood RNA Tube (PreAnalytiX GmbH, Hombrechtikon, Switzerland) from healthy volunteers as well as from OSCC patients before tumor removal. The samples were carefully inverted 8-10 times, incubated at room temperature for two hours and stored at $-20^{\circ} \mathrm{C}$ for 24 hours. Storage up to RNA isolation was carried out at $-80^{\circ} \mathrm{C}$.

\section{Isolation of mRNA and RT-qPCR analysis}

Whole RNA was extracted using miRNeasy miniKit (Qiagen, Hilden, Germany) for tissue samples and the PAXgeneBlood miRNA Kit (PreAnalytiX GmbH, Hombrechtikon, Switzerland) for blood samples. Subsequently, the RNA samples were stored at $-80^{\circ} \mathrm{C}$ until expression analysis by RT-qPCR analyses.

\section{Real-time quantitative reverse transcription- PCR (RT-qPCR) analysis}

The total-RNA was transcribed into cDNA using the Transcriptor High-Fidelity cDNA Synthesis Kit according to the manufacturer's recommendations (Roche, Mannheim, Germany). For quantification of PDL1 expression gene-specific primer for three isoforms (transcript variants 1,2 and 4) of the gene were used (Table 2). The PD-L1 gene has four splice variants. Variants 1, 2 and 4 are biological active and were analyzed in the current study. Splice variant 3 of PD-L1, a pseudogene was not analyzed, as it is not translated. Two splice variants (PD-L1 variant 1 and 2 named amplicon PD-L1_2 and PD-L1 variant 1 and 4 named amplicon PD-L1_4) were simultaneously amplified in each PCR-reaction (Table 2). For amplification, the QuantiTect SYBR ${ }^{\circledR}$ Green PCR Kit (Qiagen) was applied. Data acquisition and analysis was performed using the ABI Prism 7300 of Applied Biosystems (ThermoFisher Scientific Inc., Waltham, MA, USA). The values of RT-qPCR analyses were normalized by the $\triangle \mathrm{CT}$ method using GAPDH as internal control. The relative quantification of differences in gene expression between the two groups was based on the cycle threshold method $(\Delta \Delta \mathrm{CT}$-method, RQ $=2-\Delta \Delta \mathrm{CT})$ using Microsoft Excel 2016.

\section{Statistical analysis of RT-qPCR}

For statistical evaluation of the RT-qPCR analyses, the program IBM SPPS Statistics 22 (Chicago, IL, USA) was applied. The average of duplicate $\Delta \mathrm{CT}$ values of each sample was used for the data results. Expression data were controlled for normal distribution by Shapiro-Wilk test. Furthermore, the average values of all $\Delta \mathrm{CT}$ within a group were calculated and used to determine relative quantification (RQ) of the examined genes between the two groups by the $\triangle \Delta C T$ method. Twofold changes in mRNA expression rates $(2 \leq \mathrm{RQ} \leq 0.5)$ were defined as statistically relevant. Statistical relevance of the apparent expression between the two groups was analyzed by Mann-Whitney U-test. P-values $\leq 0.05$ were considered to indicate a statistically significant result. Based on $\Delta \mathrm{CT}$ values graphical diagrams are plotted as Box-Whisker plots which represent the median, the interquartile range, standard deviation, minimum and maximum values of mRNA expression.

In order to assess the discriminatory accuracy of the marker for distinguishing between two groups, receiver operator characteristic (ROC) curves were created using the expression profile of each differentially expressed mRNA. The value for the area under the ROC curve (AUC) defines the usefulness of a mRNA with respect to its ability to separate the tumor tissue samples from those of healthy volunteers. Additionally, by using the ROC curve the highest Youden index was determined. This value is associated with the threshold value, also named "cut-off-point" (COP) for the biological marker. The COP indicates which value of decreased or increased expression is relevant for the discrimination between malignant and normal samples and allows assigning a particular sample to a certain group [27].

Based on these COPs, the two groups were divided into two subgroups which showed an expression rate over 
or under the COP. Afterwards, associations between altered mRNA expression, malignancy and histomorphological parameters were calculated by the Chi-square test ( $\chi^{2}$ test).

\section{CONCLUSIONS}

PD-L1 expression in OSCC tumor tissue was significantly higher than in healthy oral mucosa. PDL1 expression in the peripheral blood of OSCC patients was associated with high tumor grading and metastatic disease $(\mathrm{N}+)$. This indicates an association between more aggressive behavior of the tumor and a systemic state of immune tolerance.

In future studies, PD-L1 expression should also be analyzed in precursor lesions of OSCC to clarify the role of PD-L1 signaling during early stages of malignant transformation. Such studies might pave the way for establishing novel diagnostic markers that would reliably predict the risk of malignant transformation of oral leukoplakia to OSCC and thus enable the use of immune modulatory therapy concepts already in early stages of OSCC tumorigenesis.

\section{Author contributions}

The authors' initials are used. JR and MW formulated the hypothesis, applied for grant support, initiated and conducted the study, interpreted the data and wrote the manuscript. JR established the methods and supervised the experimental study. FN formulated the hypothesis and contributed relevantly to the manuscript. $\mathrm{CB}$ and JR collected the tissue and blood samples. AA verified the pathologic diagnoses. AA, FN, MB and RP contributed to the discussion of results and critically reviewed and edited the manuscript. All authors read and approved the final manuscript.

\section{ACKNOWLEDGMENTS}

The authors thank the research technician Andrea Krautheim-Zenk for assistance performing RNA isolation and RT-qPCR analysis.

\section{CONFLICTS OF INTEREST} interests.

The authors declare that they have no competing

\section{FUNDING}

This study was funded by the Deutsche Forschungsgemeinschaft (DFG) grant no. WE5752/1-1 and by the Interdisciplinary Center of Clinical Research (IZKF) at the University Hospital of the University Erlangen-Nürnberg (FAU).

\section{REFERENCES}

1. Chen DS, Mellman I. Oncology meets immunology: the cancer-immunity cycle. Immunity. 2013; 39:1-10. https:// doi.org/10.1016/j.immuni.2013.07.012.

2. Lawrence MS, Stojanov P, Polak P, Kryukov GV, Cibulskis $\mathrm{K}$, Sivachenko A, Carter SL, Stewart C, Mermel CH, Roberts SA, Kiezun A, Hammerman PS, McKenna A, et al. Mutational heterogeneity in cancer and the search for new cancer-associated genes. Nature. 2013; 499:214-8. https:// doi.org/10.1038/nature12213.

3. Hirai M, Kitahara H, Kobayashi Y, Kato K, Bou-Gharios G, Nakamura H, Kawashiri S. Regulation of PD-L1 expression in a high-grade invasive human oral squamous cell carcinoma microenvironment. Int J Oncol. 2017; 50:41-8. https://doi.org/10.3892/ijo.2016.3785.

4. Weber M, Buttner-Herold M, Hyckel P, Moebius P, Distel L, Ries J, Amann K, Neukam FW, Wehrhan F. Small oral squamous cell carcinomas with nodal lymphogenic metastasis show increased infiltration of M2 polarized macrophages--an immunohistochemical analysis. J Craniomaxillofac Surg. 2014; 42:1087-94. https://doi. org/10.1016/j.jcms.2014.01.035.

5. Galon J, Mlecnik B, Bindea G, Angell HK, Berger A, Lagorce C, Lugli A, Zlobec I, Hartmann A, Bifulco C, Nagtegaal ID, Palmqvist R, Masucci GV, et al. Towards the introduction of the 'Immunoscore' in the classification of malignant tumours. J Pathol. 2014; 232:199-209. https:// doi.org/10.1002/path.4287.

6. Yao S, Chen L. PD-1 as an immune modulatory receptor. Cancer J. 2014; 20:262-4. https://doi.org/10.1097/ PPO.0000000000000060.

7. Zou W, Chen L. Inhibitory B7-family molecules in the tumour microenvironment. Nat Rev Immunol. 2008; 8:46777. https://doi.org/10.1038/nri2326.

8. Ceeraz S, Nowak EC, Noelle RJ. B7 family checkpoint regulators in immune regulation and disease. Trends Immunol. 2013; 34:556-63. https://doi.org/10.1016/j. it.2013.07.003.

9. Pardoll DM. The blockade of immune checkpoints in cancer immunotherapy. Nat Rev Cancer. 2012; 12:252-64. https:// doi.org/10.1038/nrc3239.

10. Troeltzsch M, Woodlock T, Pianka A, Otto S, Troeltzsch M, Ehrenfeld M, Knosel T. Is There Evidence for the Presence and Relevance of the PD-1/PD-L1 Pathway in Oral Squamous Cell Carcinoma? Hints From an Immunohistochemical Study. J Oral Maxillofac Surg. 2016; 75:969-977. https://doi.org/10.1016/j.joms.2016.11.006.

11. Straub M, Drecoll E, Pfarr N, Weichert W, Langer R, Hapfelmeier A, Gotz C, Wolff KD, Kolk A, Specht K. CD274/PD-L1 gene amplification and PD-L1 protein expression are common events in squamous cell carcinoma of the oral cavity. Oncotarget. 2016; 7:12024-34. https://doi.org/10.18632/oncotarget.7593. 
12. Chen TC, Wu CT, Wang CP, Hsu WL, Yang TL, Lou PJ, Ko JY, Chang YL. Associations among pretreatment tumor necrosis and the expression of HIF-1alpha and PD-L1 in advanced oral squamous cell carcinoma and the prognostic impact thereof. Oral Oncol. 2015; 51:1004-10. https://doi. org/10.1016/j.oraloncology.2015.08.011.

13. Lin YM, Sung WW, Hsieh MJ, Tsai SC, Lai HW, Yang SM, Shen KH, Chen MK, Lee H, Yeh KT, Chen CJ. High PD-L1 Expression Correlates with Metastasis and Poor Prognosis in Oral Squamous Cell Carcinoma. PLoS One. 2015; 10:e0142656. https://doi.org/10.1371/journal. pone. 0142656 .

14. Tanday S. Nivolumab for recurrent or metastatic head and neck cancer. Lancet Oncol. 2016; 17:e483. https://doi. org/10.1016/S1470-2045(16)30505-8.

15. Brahmer JR, Tykodi SS, Chow LQ, Hwu WJ, Topalian SL, Hwu P, Drake CG, Camacho LH, Kauh J, Odunsi K, Pitot HC, Hamid O, Bhatia S, et al. Safety and activity of anti-PD-L1 antibody in patients with advanced cancer. N Engl J Med. 2012; 366:2455-65. https://doi.org/10.1056/NEJMoa1200694.

16. Wang X, Bao Z, Zhang X, Li F, Lai T, Cao C, Chen Z, Li W, Shen H, Ying S. Effectiveness and safety of PD-1/PDL1 inhibitors in the treatment of solid tumors: a systematic review and meta-analysis. Oncotarget. 2017; 8:5990159914. https://doi.org/10.18632/oncotarget.18316.

17. Drake CG. Combination immunotherapy approaches. Ann Oncol. 2012; 23:viii41-6. https://doi.org/10.1093/ annonc/mds 262 .

18. Zandberg DP, Strome SE. The role of the PD-L1:PD-1 pathway in squamous cell carcinoma of the head and neck. Oral Oncol. 2014; 50:627-32. https://doi.org/10.1016/j. oraloncology.2014.04.003.

19. Pai SI, Zandberg DP, Strome SE. The role of antagonists of the PD-1:PD-L1/PD-L2 axis in head and neck cancer treatment. Oral Oncol. 2016; 61:152-8. https://doi. org/10.1016/j.oraloncology.2016.08.001.

20. EMA. (2017). Nivolumab approval: http://www.ema. europa.eu/docs/de_DE/document_library/EPAR_Product_Information/human/003985/WC500189765.pdf.

21. FDA. (2017). Pembrolizumab approval: https://www. fda.gov/Drugs/InformationOnDrugs/ApprovedDrugs/ ucm515627.htm.

22. Ran X, Yang K. Inhibitors of the PD-1/PD-L1 axis for the treatment of head and neck cancer: current status and future perspectives. Drug Des Devel Ther. 2017; 11:2007-14. https://doi.org/10.2147/DDDT.S140687.

23. Chen J, Jiang CC, Jin L, Zhang XD. Regulation of PD-L1: a novel role of pro-survival signalling in cancer. Ann Oncol. 2016; 27:409-16. https://doi.org/10.1093/annonc/mdv615.

24. Gettinger SN, Horn L, Gandhi L, Spigel DR, Antonia SJ, Rizvi NA, Powderly JD, Heist RS, Carvajal RD, Jackman DM, Sequist LV, Smith DC, Leming P, et al. Overall Survival and Long-Term Safety of Nivolumab (AntiProgrammed Death 1 Antibody, BMS-936558, ONO-4538) in Patients With Previously Treated Advanced Non-SmallCell Lung Cancer. J Clin Oncol. 2015; 33:2004-12. https:// doi.org/10.1200/JCO.2014.58.3708.

25. Patel SG, Shah JP. TNM staging of cancers of the head and neck: striving for uniformity among diversity. CA Cancer J Clin. 2005; 55:242-58; quiz 61-2, 64.

26. Huang SH, O'Sullivan B. Overview of the 8th Edition TNM Classification for Head and Neck Cancer. Curr Treat Options Oncol. 2017; 18:40. https://doi.org/10.1007/ s11864-017-0484-y.

27. Fluss R, Faraggi D, Reiser B. Estimation of the Youden Index and its associated cutoff point. Biom J. 2005; 47:45872.

28. De Meulenaere A, Vermassen T, Aspeslagh S, Huvenne W, Van Dorpe J, Ferdinande L, Rottey S. Turning the tide: Clinical utility of PD-L1 expression in squamous cell carcinoma of the head and neck. Oral Oncol. 2017; 70:34 42. https://doi.org/10.1016/j.oraloncology.2017.05.002.

29. Ritprajak P, Azuma M. Intrinsic and extrinsic control of expression of the immunoregulatory molecule PDL1 in epithelial cells and squamous cell carcinoma. Oral Oncol. 2015; 51:221-8. https://doi.org/10.1016/j. oraloncology.2014.11.014.

30. Cho YA, Yoon HJ, Lee JI, Hong SP, Hong SD. Relationship between the expressions of PD-L1 and tumor-infiltrating lymphocytes in oral squamous cell carcinoma. Oral Oncol. 2011; 47:1148-53. https://doi.org/10.1016/j. oraloncology.2011.08.007.

31. Oliveira-Costa JP, de Carvalho AF, da Silveira da GG, Amaya P, Wu Y, Park KJ, Gigliola MP, Lustberg M, Buim ME, Ferreira EN, Kowalski LP, Chalmers JJ, Soares FA, et al. Gene expression patterns through oral squamous cell carcinoma development: PD-L1 expression in primary tumor and circulating tumor cells. Oncotarget. 2015; 6:20902-20. https://doi.org/10.18632/oncotarget.3939.

32. Satgunaseelan L, Gupta R, Madore J, Chia N, Lum T, Palme CE, Boyer M, Scolyer RA, Clark JR. Programmed cell death-ligand 1 expression in oral squamous cell carcinoma is associated with an inflammatory phenotype. Pathology. 2016; 48:574-80. https://doi.org/10.1016/j. pathol.2016.07.003.

33. Patel SJ, Sanjana NE, Kishton RJ, Eidizadeh A, Vodnala SK, Cam M, Gartner JJ, Jia L, Steinberg SM, Yamamoto TN, Merchant AS, Mehta GU, Chichura A, et al. Identification of essential genes for cancer immunotherapy. Nature. 2017; 548:537-42. https://doi.org/10.1038/nature23477.

34. Shin DS, Zaretsky JM, Escuin-Ordinas H, Garcia-Diaz A, Hu-Lieskovan S, Kalbasi A, Grasso CS, Hugo W, Sandoval S, Torrejon DY, Palaskas N, Rodriguez GA, Parisi G, et al. Primary Resistance to PD-1 Blockade Mediated by JAK1/2 Mutations. Cancer Discov. 2017; 7:188-201. https://doi. org/10.1158/2159-8290.CD-16-1223.

35. Kleinovink JW, Marijt KA, Schoonderwoerd MJA, van Hall T, Ossendorp F, Fransen MF. PD-L1 expression on 
malignant cells is no prerequisite for checkpoint therapy. Oncoimmunology. 2017; 6:e1294299. https://doi.org/10.10 80/2162402X.2017.1294299.

36. Lechner A, Schlosser H, Rothschild SI, Thelen M, Reuter S, Zentis P, Shimabukuro-Vornhagen A, Theurich S, Wennhold K, Garcia-Marquez M, Tharun L, Quaas A, Schauss A, et al. Characterization of tumor-associated T-lymphocyte subsets and immune checkpoint molecules in head and neck squamous cell carcinoma. Oncotarget. 2017; 8:4441844433. https://doi.org/10.18632/oncotarget.17901.

37. Gibbons Johnson RM, Dong H. Functional Expression of Programmed Death-Ligand 1 (B7-H1) by Immune Cells and Tumor Cells. Front Immunol. 2017; 8:961. https://doi. org/10.3389/fimmu.2017.00961.

38. Heneghan HM, Miller N, Lowery AJ, Sweeney KJ, Newell J, Kerin MJ. Circulating microRNAs as novel minimally invasive biomarkers for breast cancer. Ann Surg. 2010; 251:499-505. https://doi.org/10.1097/ SLA.0b013e3181cc939f.

39. Heneghan HM, Miller N, Kerin MJ. Circulating microRNAs: promising breast cancer Biomarkers. Breast Cancer Res. 2011; 13:402; author reply 3. https://doi. org/10.1186/bcr2798.

40. Hausler SF, Keller A, Chandran PA, Ziegler K, Zipp K, Heuer S, Krockenberger M, Engel JB, Honig A, Scheffler M, Dietl J, Wischhusen J. Whole blood-derived miRNA profiles as potential new tools for ovarian cancer screening. Br J Cancer. 2010; 103:693-700. https://doi.org/6605833.

41. Harada K, Dong X, Estrella JS, Correa AM, Xu Y, Hofstetter WL, Sudo K, Onodera H, Suzuki K, Suzuki A, Johnson RL, Wang Z, Song S, et al. Tumor-associated macrophage infiltration is highly associated with PD-L1 expression in gastric adenocarcinoma. Gastric Cancer. 2017 Aug 11. https://doi.org/10.1007/s10120-017-0760-3. [Epub ahead of print].

42. Heeren AM, Punt S, Bleeker MC, Gaarenstroom KN, van der Velden J, Kenter GG, de Gruij1 TD, Jordanova ES. Prognostic effect of different PD-L1 expression patterns in squamous cell carcinoma and adenocarcinoma of the cervix. Mod Pathol. 2016; 29:753-63. https://doi.org/10.1038/ modpathol.2016.64.

43. Chen W, Wang J, Jia L, Liu J, Tian Y. Attenuation of the programmed cell death-1 pathway increases the M1 polarization of macrophages induced by zymosan. Cell Death Dis. 2016; 7:e2115. https://doi.org/10.1038/ cddis.2016.33.

44. Grimm M, Feyen O, Coy JF, Hofmann H, Teriete P, Reinert $\mathrm{S}$. Analysis of circulating CD14+/CD16+ monocyte-derived macrophages (MDMs) in the peripheral blood of patients with oral squamous cell carcinoma. Oral Surg Oral Med Oral Pathol Oral Radiol. 2016; 121:301-6. https://doi. org/10.1016/j.oooo.2015.10.024.

45. Wehrhan F, Buttner-Herold M, Hyckel P, Moebius P, Preidl R, Distel L, Ries J, Amann K, Schmitt C, Neukam FW, Weber M. Increased malignancy of oral squamous cell carcinomas (oscc) is associated with macrophage polarization in regional lymph nodes - an immunohistochemical study. BMC Cancer. 2014; 14:522. https://doi.org/10.1186/1471-2407-14-522.

46. Mantovani A, Marchesi F, Malesci A, Laghi L, Allavena P. Tumour-associated macrophages as treatment targets in oncology. Nat Rev Clin Oncol. 2017; 14:399-416. https:// doi.org/10.1038/nrclinonc.2016.217.

47. Kubota K, Moriyama M, Furukawa S, Rafiul H, Maruse Y, Jinno T, Tanaka A, Ohta M, Ishiguro N, Yamauchi M, Sakamoto M, Maehara T, Hayashida JN, et al. CD163+CD204+ tumor-associated macrophages contribute to $\mathrm{T}$ cell regulation via interleukin-10 and $\mathrm{PD}-\mathrm{L} 1$ production in oral squamous cell carcinoma. Sci Rep. 2017; 7:1755. https://doi.org/10.1038/s41598-017-01661-z.

48. Nagasaka M, Zaki M, Kim H, Raza SN, Yoo G, Lin HS, Sukari A. PD1/PD-L1 inhibition as a potential radiosensitizer in head and neck squamous cell carcinoma: a case report. J Immunother Cancer. 2016; 4:83. https://doi. org/10.1186/s40425-016-0187-0. 